\title{
Design and Implementation of Sensorless Electronic Water Pump for Automobile
}

\author{
Junliang Han ${ }^{1,2,3}$, Hui Song ${ }^{4}$, Changhong Feng ${ }^{2}$, Xiangqing Zhou ${ }^{2}$, Chuansheng Tang ${ }^{1}$, \\ Zhengyong Duan ${ }^{1}$, Jinfeng Gao ${ }^{3}$ \\ ${ }^{1}$ Shool of Mechanical and Automotive Engineering, Nanyang Institute of Technology, Nanyang, China \\ ${ }^{2}$ Henan Province Xixia Automobile Water Pump Co., Ltd., Xixia, China \\ ${ }^{3}$ College of Electrical Engineering, Zhengzhou University, Zhengzhou, China \\ ${ }^{4}$ Department of Central Air-conditioning, Midea Group Co., Ltd., Foshan, China
}

Email address:

hanhanhgd8000@163.com (Junliang Han), dongfeng8000@163.com (Hui Song), tcs111@163com (Chuansheng Tang), dzyai@163com (Zhengyong Duan), dianqi2020@163.com (Jinfeng Gao)

\section{To cite this article:}

Junliang Han, Hui Song, Changhong Feng, Xiangqing Zhou, Chuansheng Tang, Zhengyong Duan, Jinfeng Gao. Design and Implementation of Sensorless Electronic Water Pump for Automobile. Journal of Electrical and Electronic Engineering. Vol. 6, No. 1, 2018 , pp. $31-39$. doi: $10.11648 /$ j.jeee.20180601.16

Received: January 22, 2018; Accepted: March 6, 2018; Published: March 9, 2018

\begin{abstract}
The electronic water pump will be used more and more widely in the new energy vehicles and other special vehicles. A sensorless electronic water pump for automobile is designed and implemented with the brushless direct current motor (BLDCM) as the driving motor. A sensorless magnetic field oriented control (FOC) scheme using sliding mode observer (SMO) is applied for the motor control. A novel SMO and the phase-locked loop (PLL) for reducing the chattering phenomenon are used to estimate rotor velocity/position from the back electromotive force (EMF), in which a continuous saturation function is applied instead of the sign function. A robust $I-f$ startup strategy is introduced. The hardware circuit design and software algorithm design are presented. The experimental system is set up and some experimental results are demonstrated. The effectiveness and correctness of the proposed hardware design and the software scheme are validated. Experimental results show that the developed electronic water pump is reasonable and feasible with a high cost performance.
\end{abstract}

Keywords: Electronic Water Pump, Brushless DC Motor, Field Oriented Control, Sliding Mode Observer, Phase-Locked Loop

\section{Introduction}

The new energy vehicles and other special vehicles use the micro water pumps for water circulation, cooling or the water supply system. The electronic water pump will be used more and more widely relative to the traditional mechanical water pump with the characteristics of flexible control, energy saving and convenient usage. The electronic water pump is driven with the electric motor. The BLDC motor (BLDCM) has the advantages with simple structure, no commutation spark, reliable operation, easy maintenance and so on. These motors can provide high-power density, high efficiency and torque to inertia ratio when compared with DC and induction motors. However, the high performance for BLDCM needs the accurate rotor position information. But the position sensors require the additional mounting space, and could increase the cost and degrade the reliability in harsh environments. Thus the reduction of sensors is desirable to reduce cost, simplify hardware and increase reliability [1].

The BLDCM with the back EMF similar to sine wave DC which characteristics can be represented with the surfacemounted permanent magnet synchronous motor (SPMSM). Thus this type of BLDCM can be controlled with the method for the SPMSM. In recent years, many control strategies aiming at realizing the sensorless control of PMSM are reported in the literatures [2]-[32]. All these methods can be mainly classified into two categories: signal injection techniques and speed observers. The signal injection techniques offer a satisfying solution both for standstill and low speed operation, but they require high precision in the 
measure and increase the complexity of the hardware and software control system. What is more, the signal injection techniques will bring high-frequency noise which leads to system performance degradation. Therefore, the speed observers are widely used in the sensorless control scheme. Model reference adaptive method [2]-[8] and extended Kalman filtering method [9]-[12] belong to the scope of method based on observer. They rely on the accuracy of the motor model to some extent, which affects the estimation performance [17]. Sliding model observer (SMO) [15]-[32] are known to be insensitive to parameter variations and disturbances, which are suitable for medium speed or high speed running condition of PMSM. However, the conventional SMO method suffers the chattering problem to the discontinuous switching control. A novel SMO method is adopted in order to weaken the chattering problem and increase estimation accuracy of rotor position. In this method, the conventional switch function is replaced by the sigmoid function [17], [19]. Further, the PLL is used to calculate the rotor position after the back-EMF is estimated from the novel SMO [15], [22], [24], [31].

An electronic water pump for automobile is designed and implemented in the paper. A BLDCM with the back EMF similar to sine wave DC is used as the driving motor for the electronic water pump. A sensorless FOC scheme using SMO scheme for electronic water pump control is presented. A novel SMO method with PLL is adopted in order to weaken the chattering problem of conventional SMO and increase estimation accuracy of rotor position. In this observer, the sign function in traditional SMO is replaced by the saturation function. Further, the PLL is used to calculate the rotor position after the back-EMF has been estimated from the novel SMO. The designs of hardware circuit and software realization algorithm are implemented. The realization of the presented control algorithm is implemented in the Advanced RISC Machine (ARM) chip. The experiment system is set up and the experiments are conducted. The experimental results show that the aims of high control precision and high stability are attained. The targets of flow and lift for the electronic water pump are reached. The effectiveness and correctness of the proposed hardware design and the sensorless control are validated.

\section{Hardware Design Scheme for Electronic Water Pump}

The hardware circuit of the electronic water pump consists of power circuit, sampling circuit, communication circuit and control circuit. The power circuit includes the Electro Magnetic Compatibility (EMC) circuit, anti-reverse circuit and 3-phase $\mathrm{H}$ Bridge circuit. The function of power transformation is realized in the power circuit. The sampling circuit includes the current sampling circuit and temperature sampling circuit. The communication circuit is composed of pulse width modulation (PWM) communication circuit, local interconnect network (LIN) communication circuit, or
Controller Area Network (CAN) communication circuit. The communication between the electronic water pump and the vehicle controller unit (VCU) is implemented in the communication circuit. The control circuit is composed of the main control chip and its peripheral circuit. Signal processing and control algorithm are realized in the control circuit.

In the design, a motor control chip of Infineon Corporation named TLE9879QXA20 is used as the main control chip. It is a single-chip three-phase motor driver IC, which integrates the industry standard ARM Cortex M3 kernel. It includes six fully integrated NFET drivers optimized to drive a 3-phase motor via six external power NFETs, and a charge pump enabling low voltage operation and programmable current along with current slope control for optimized EMC behavior. Its peripheral set includes a current sensor, a successive approximation ADC synchronized with the capture and compare unit for PWM control and 16-bit timers. A LIN transceiver is also integrated to enable communication to the device along with a number of general purpose I/Os. It includes an on-chip linear voltage regulator to supply external loads.

The communication circuit uses the PWM/LIN communication mode, which is used for communication between the electronic water pump and the VCU. The system block diagram for electronic water pump is shown in Figure 1. The system includes micro processor uint (MPU), EMC circuit, anti-reverse circuit, 3-phase $\mathrm{H}$ bridge, current sampling circuit and BLDCM. The anti-reverse circuit adopts an $\mathrm{N}$ type MOSFET as the power switching device. When working normally, the $\mathrm{N}$ type MOSFET operates in synchronous rectification mode, making the reverse protection circuit has higher efficiency. The single resistance sampling scheme is adopted in the current sampling circuit. The bus current is sampled and then the three-phase current can be obtained through the algorithm in MPU.

In the process of installation or maintenance of electronic water pump, if the polarity of power supply is reversed, a large reverse current will be generated through the internal parasitic diodes within the power NFETs, which will destroy the controller and vehicle power in severe cases. So an anti-reverse circuit is very necessary for electronic water pump.

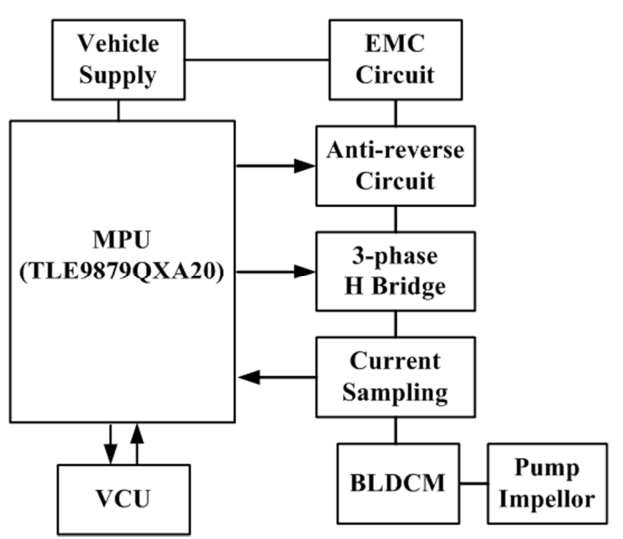

Figure 1. System block diagram for electronic water pump. 
The schematic of the anti-reverse circuit is shown in Figure 2. It includes the capacitor $\mathrm{C} 1$, the resistor $\mathrm{R} 1$, the diode $\mathrm{D} 1$ and D2 and $\mathrm{N}$ type MOSFET VT1. The capacitor $\mathrm{C} 1$, the resistor R1, diode D1 and D2 constitute a voltage-doubling circuit.

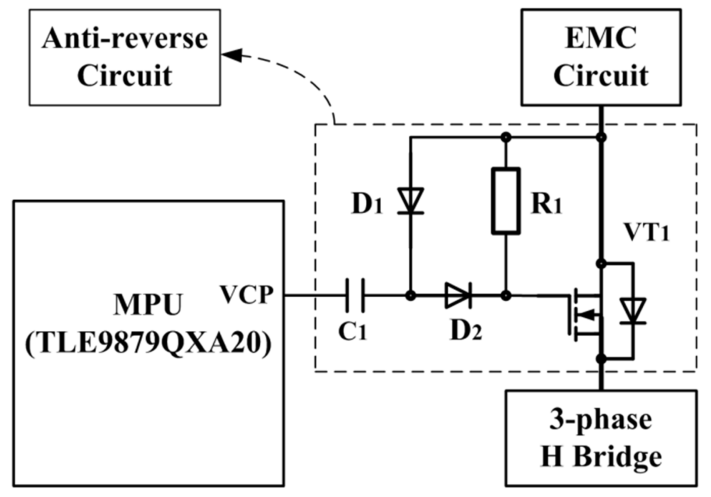

Figure 2. Schematic of the anti-reverse circuit.

During the normal operation, the VCP pin of TLE9879QXA20 drives voltage-doubling circuit with the continuous high-frequency square wave signals. Then the output doubled voltage drives the $\mathrm{N}$ type MOSFET VT1, making VT1 in synchronous rectifier conduction mode. Thus the power loss produced this circuit is much less than that by using diode as the power switch device. If the polarity of the power supply is reversed, due to the role of pull-down resistor $\mathrm{R} 1$, the $\mathrm{N}$ type MOSFET VT1 is shut off, and the power circuit is disconnected. Thus the entire system of electronic water pump is powered off and the anti-reverse protection function is realized.

\section{Sensorless Control Scheme for Electronic Water Pump}

The sensorless control scheme is based on FOC and I-f startup strategy. It includes two sequence steps. The first step is the I-f startup and the second step is the sensorless FOC working using the novel SMO and PLL.

\subsection{Field Oriented Control}

Sensorless control scheme for electronic water pump is demonstrated in Figure 3. The basic idea of FOC is to synchronize permanent magnets by vector transformation. The excitation current component ( $\mathrm{d}$ axis component) and the torque current component ( $\mathrm{q}$ axis component) are controlled respectively, so that the permanent magnet synchronous motors have the same control characteristics as the DC motors.

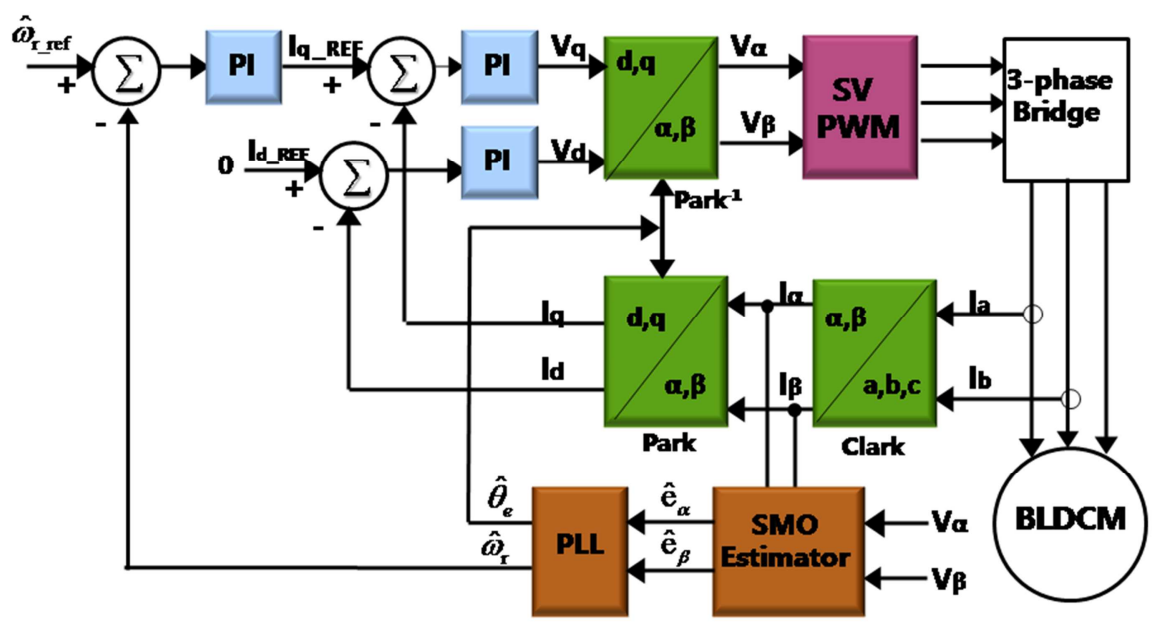

Figure 3. Sensorless control scheme for electronic water pump.

The FOC control algorithm consists of PI controllers, SVPWM transformation and position/speed estimator. The PI controllers include the outer speed closed-loop controller and the inner current closed-loop controllers. The first PI controller is used for the closed-loop speed control. The second PI controller is used for the control of q-axis component Iq. And the third PI controllers is used for the control of d-axis component Id. The d-axis component Id and the q-axis component Iq can be obtained through the Clark transformation and the Park transformation from the three-phase currents. The sliding mode state observer and the Phase-Locked Loop constitute the position/speed estimator, which are used to estimate the position angle of the rotor and the rotation speed of the motor.

\subsection{Novel Sliding Mode Observer}

The characteristics of BLDCM with back-EMF similar to sine wave can be represented with the SPMSM. The mathematical model of SPMSM is described in $\mathrm{d}-\mathrm{q}$ synchronous rotating frame as follows

$$
\left[\begin{array}{l}
v_{d} \\
v_{q}
\end{array}\right]=\left[\begin{array}{ll}
R_{s}+s L_{s} & -\omega_{e} L_{s} \\
-\omega_{e} L_{s} & R_{s}+s L_{s}
\end{array}\right]\left[\begin{array}{l}
i_{d} \\
i_{q}
\end{array}\right]+\left[\begin{array}{l}
0 \\
\omega_{e} \Psi_{f}
\end{array}\right]
$$

where $v_{d}, v_{q}$ are the $\mathrm{d}$ and $\mathrm{q}$ axis voltages; $i_{d}, i_{q}$ are the $\mathrm{d}$ 
and $\mathrm{q}$ axis currents, and $R_{s}$ is the phase winding resistance; $L_{s}$ is the phase inductance, here $L_{s}=L_{d}=L_{q}$, and $L_{d}, L_{q}$ are the $\mathrm{d}$ and $\mathrm{q}$ axis inductances; $\omega_{e}$ is the rotating speed of magnet flux; $\Psi_{f}$ is the permanent magnet flux linkage.

The mathematical model of SPMSM in $\alpha-\beta$ coordinate frame can be expressed as the following equation

$$
\left\{\begin{array}{l}
\frac{d i_{\alpha}}{d t}=-\frac{R_{S}}{L_{S}} i_{\alpha}+\frac{1}{L_{S}} v_{\alpha}-\frac{1}{L_{S}} e_{\alpha} \\
\frac{d i_{\beta}}{d t}=-\frac{R_{S}}{L_{S}} i_{\beta}+\frac{1}{L_{S}} v_{\beta}-\frac{1}{L_{S}} e_{\beta}
\end{array}\right.
$$

$$
\left\{\begin{array}{l}
e_{\alpha}=-\omega_{e} \Psi_{f} \sin \theta_{e} \\
e_{\beta}=\omega_{e} \Psi_{f} \cos \theta_{e}
\end{array}\right.
$$

where $\theta_{e}$ is the electric angle.

The schematic diagram of the novel SMO proposed in the paper is shown in Figure 4. It consists of a sliding mode current observer, a saturation function, and a low-pass filter. The saturation function is defined as follows

$$
F(x)=\left\{\begin{array}{lr}
k \cdot x ; & -x_{0} \leq x \leq x_{0} \\
A ; & x>x_{0} \\
-A ; & x<-x_{0}
\end{array}\right.
$$

where $v_{\alpha}, v_{\beta}$ are the $\alpha$ and $\beta$ axis voltages; $i_{\alpha}, i_{\beta}$ are the $\alpha$ and $\beta$ axis currents; $e_{\alpha}, e_{\beta}$ are the $\alpha$ and $\beta$ axis back-EMF, and they can be written as follows

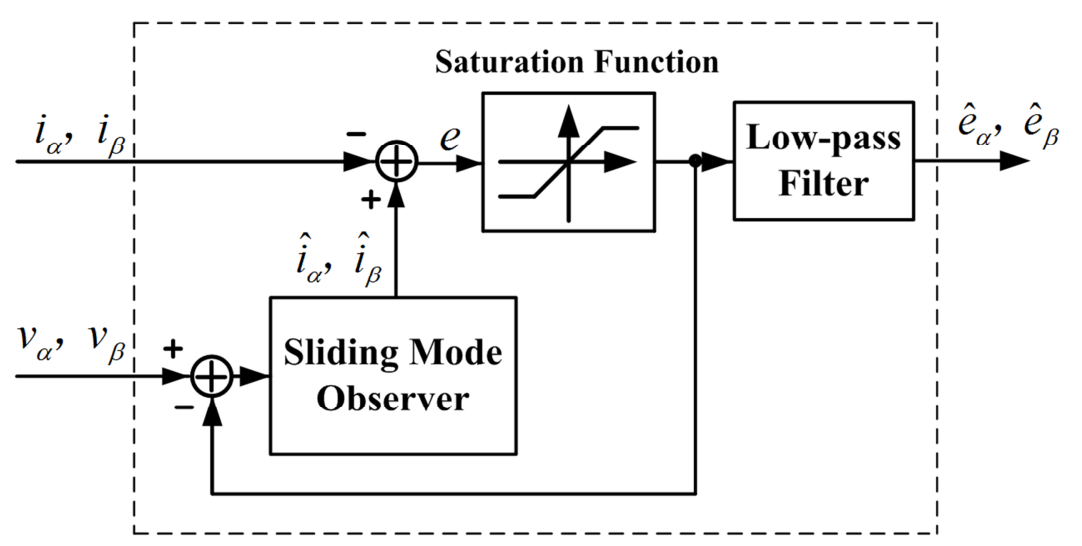

Figure 4. Schematic diagram of the novel SMO.

The low-pass filter adopts one-order low-pass filter, which can be represented in the frequency domain as follows

$$
Y(s)=\frac{\omega_{c}}{s+\omega_{c}} X(s)
$$

where $\omega_{c}$ is the cutting-off frequency of the low-pass filter.

In the observer, the currents $i_{\alpha}, i_{\beta}$ in the $\alpha$ and $\beta$ axis, voltages $v_{\alpha}, v_{\beta}$ in the $\alpha$ and $\beta$ axis are the input variables. And the estimated back-EMF $\hat{e}_{\alpha}, \hat{e}_{\beta}$ in the $\alpha$ and $\beta$ axis are the output results. The estimated current will be compared with the actual measured current $i_{\alpha}, i_{\beta}$, then the error through the saturation function and the low-pass filter will generate the estimated back-EMF $\hat{e}_{\alpha}, \hat{e}_{\beta}$.

The novel sliding mode observer is applied, and the formulation is shown as follows

$$
\left\{\begin{array}{l}
\frac{d \hat{i}_{\alpha}}{d t}=-\frac{R_{S}}{L_{S}} \hat{i}_{\alpha}+\frac{1}{L_{S}} v_{\alpha}-\frac{1}{L_{S}} F\left(\hat{i}_{\alpha}-i_{\alpha}\right) \\
\frac{d \hat{i}_{\beta}}{d t}=-\frac{R_{S}}{L_{S}} \hat{i}_{\beta}+\frac{1}{L_{S}} v_{\beta}-\frac{1}{L_{S}} F\left(\hat{i}_{\beta}-i_{\beta}\right)
\end{array}\right.
$$

where $\hat{i}_{\alpha}, \hat{i}_{\beta}$ are the estimated current in $\alpha$ and $\beta$ axis.

From the formula (5) and (6), the dynamic equation of the estimated current error can be written as

$$
\left\{\begin{array}{l}
\frac{d \overline{i_{\alpha}}}{d t}=-\frac{R_{S}}{L_{S}} \overline{i_{\alpha}}+\frac{1}{L_{S}} v_{\alpha}-\frac{1}{L_{S}} F\left(\overline{i_{\alpha}}\right) \\
\frac{d \overline{i_{\beta}}}{d t}=-\frac{R_{S}}{L_{S}} \bar{i}_{\beta}+\frac{1}{L_{S}} v_{\beta}-\frac{1}{L_{S}} F\left(\overline{i_{\alpha}}\right)
\end{array}\right.
$$

where $\bar{i}_{\alpha}=\hat{i}_{\alpha}-i_{\alpha}, \bar{i}_{\beta}=\hat{i}_{\beta}-i_{\beta}$, here $\bar{i}_{\alpha}$ and $\bar{i}_{\beta}$ are defined as estimation errors. The stability condition of the sliding mode observer is as follows

$$
\overline{i_{\alpha}} \times \frac{d}{d t} \bar{i}_{\alpha}<0, \overline{i_{\beta}} \times \frac{d}{d t} \bar{i}_{\beta}<0
$$

Then from the formula (7), it can be obtained that

$$
\left\{\begin{array}{l}
\bar{i}_{\alpha} \times \frac{d \bar{i}_{\alpha}}{d t}=\left[-R_{S} \bar{i}_{\alpha}^{2}+\bar{i}_{\alpha} \times\left(v_{\alpha}-F\left(\bar{i}_{\alpha}\right)\right)\right] / L_{S} \\
\bar{i}_{\beta} \times \frac{d \bar{i}_{\beta}}{d t}=\left[-R_{S} \bar{i}_{\beta}^{2}+\bar{i}_{\beta} \times\left(v_{\beta}-F\left(\bar{i}_{\beta}\right)\right)\right] / L_{S}
\end{array}\right.
$$


If the following formulas are adopted,

$$
\left\{\begin{array}{l}
e_{\alpha}=F\left(\hat{i}_{\alpha}-i_{\alpha}\right)=F\left(\overline{i_{\alpha}}\right) \\
e_{\beta}=F\left(\hat{i}_{\beta}-i_{\beta}\right)=F\left(\overline{i_{\beta}}\right)
\end{array}\right.
$$

Thus stability condition formula (8) can be satisfied. Therefore, the following equations can be obtained

$$
\frac{d \overline{i_{\alpha}}}{d t}=0, \frac{d \overline{i_{\beta}}}{d t}=0
$$

In the steady-state condition, the following results can be obtained

$$
\bar{i}=0, \overline{i_{\beta}}=0
$$

That is

$$
\hat{i}_{\alpha}=i_{\alpha}, \hat{i}_{\beta}=i_{\beta}
$$

The PLL is used to estimate the rotor position after the back-EMF has been estimated. The schematic diagram of the PLL is shown in Figure 5. The estimated back-EMF $\hat{e}_{\alpha}, \hat{e}_{\beta}$ are the input variables. The estimated rotating speed $\hat{\omega}_{e}$ and electric angle $\hat{\theta}_{e}$ are the output results. In Figure $5, \mathrm{~K}_{\mathrm{P}}$ is the Proportion coefficient, and $\mathrm{K}_{\mathrm{I}}$ is the Integral coefficient of PI controller, and $p$ is the polar pairs of the motor.

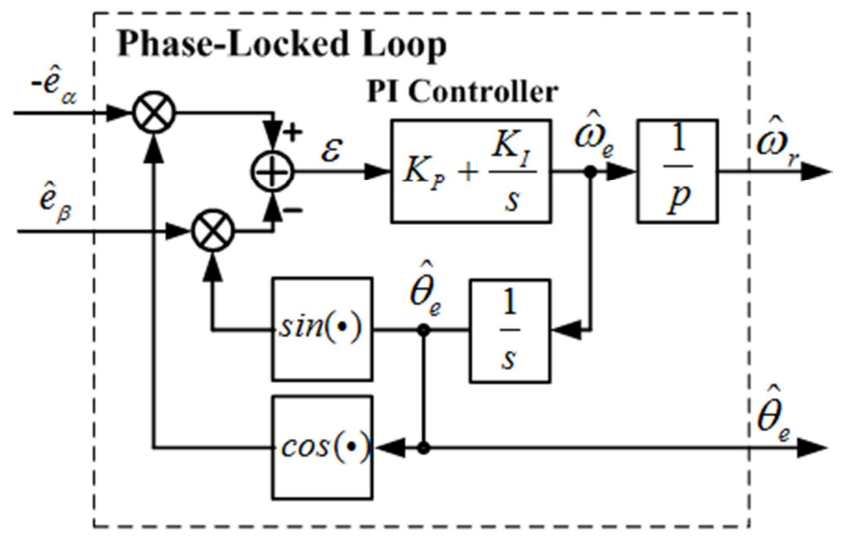

Figure 5. Schematic diagram of the Phase-Locked Loop.

The input error of PI controller can be written as

$$
\varepsilon=-\hat{e}_{\alpha} \cos \left(\hat{\theta}_{e}\right)-\hat{e}_{\beta} \sin \left(\hat{\theta}_{e}\right)
$$

Then the output of PI controller can be written as

$$
\hat{\omega}_{e}=K_{P} \varepsilon+K_{I} \int \varepsilon d t
$$

Through the PI control, the input error $\varepsilon$ will approach to zero in the steady state, that is

$$
-\hat{e}_{\alpha} \cos \left(\hat{\theta}_{e}\right)-\hat{e}_{\beta} \sin \left(\hat{\theta}_{e}\right)=0
$$

Then the estimated electric angle $\hat{\theta}_{e}$ can be obtained as follows

$$
\hat{\theta}=-\tan ^{-1} \frac{\hat{e}_{\alpha}}{\hat{e}_{\beta}}
$$

The low pass filter has a phase delay, and the angle of the electric angle $\hat{\theta}_{e}$ should be compensated. The compensated angle is as follows

$$
\Delta \theta_{e}=\tan ^{-1} \frac{\omega_{e}}{\omega_{c}}
$$

\subsection{I-f Startup Strategy}

Although BEMF theory performs dynamic response from middle to high speed region very well, it is also limited by too low BEMF at standstill and low speed. How to start PMSM from standstill is a challenge. The startup procedure should also be robust and able to work with different load situations to ensure that the drive is able to accelerate to a speed at which the back-EMF is high enough to be accurately sensed. A simple startup method could be to give dc bias currents to the phase windings at the beginning in order to align the rotor to a predetermined position [34]. A smooth transition strategy is adopted in the paper, which performs well under disturbance, high efficiency and without parameter requirement. I- $f$ startup strategy consists of three stages, and they can be expressed as follows [24], [33]-[35].

Stage 1: Speed ramp-up with constant q-axis current at initial start. The purpose of this step is to accelerate the motor from standstill to a desired speed. This step aims to allow the back-EMF signal can be sensed properly to obtain the accurate rotor position and speed information. The q-axis current command and angular frequency command are set separately as follows

$$
\begin{aligned}
& i_{q_{-} r e f}(t)=I_{q 0} \\
& \omega_{e_{-} r e f}(t)=K_{e} t
\end{aligned}
$$

where $I_{q 0}$ is a constant current, $K_{e}$ is a speed coefficient.

Stage 2: Constant speed reference with decreasing q-axis current at $\mathrm{t} 1$. An effective way to offer a smooth transition is to keep the speed constant while reducing the q-axis current. The current will approach to the value that will be generated in the FOC mode, and the rotor d-axis current will be reduced to zero. The current and torque ripples during the switching to the FOC mode will then be reduced. The q-axis current command and angular frequency command are set separately as follows

$$
\begin{gathered}
i_{q_{-} r e f}(t)=I_{q 0}-K_{i}\left(t-t_{1}\right) \\
\omega_{e_{-} r e f}(t)=\omega_{e}\left(t_{1}\right)
\end{gathered}
$$

where $\mathrm{Ki}$ is a current coefficient.

Stage 3: Switching to the sensorless FOC mode operation at the end of the stage 2. At this stage, FOC is switched in at the end of Stage 2 when the estimated rotor position is accurate 
enough. The FOC takes over the control and the q-axis current command is then determined by the speed control loop to further regulate the rotor speed [34].

The startup procedure is based on closed-loop current regulation. It can work under different load conditions and allows smooth transition from the startup procedure to the sensorless control mode.

\section{Experimental Results}

A sensorless electronic water pump for automobile is developed. The hardware circuit construction is completed and the sensorless control scheme and other algorithms are implemented in TLE9879QXA20 with the software codes. The experiment system is set up and the experiments are conducted. The physical picture of the developed electronic water pump is shown in Figure 6. It includes a BLDCM, the circuit board, connection terminal, motor end cover, pump impeller, impeller end cover and seal ring. The back-EMF coefficient of BLDCM is $1.27 \mathrm{mV} / \mathrm{rpm}$, and the polar pairs of the motor are 2 pairs. The inductance of the stator winding is $250 \mu \mathrm{H}$, and the internal resistance of the stator winding is $0.2 \Omega$. The rated voltage of the BLDCM is $12 \mathrm{~V}$, and the rated power is $60 \mathrm{~W}$. The rated speed is set to $4600 \mathrm{r} / \mathrm{min}$.

Parameters and performance tests are carried out. The temperature of the experimental environment is $25^{\circ} \mathrm{C}$, and the temperature of the circulating medium in the electronic water pump is $95^{\circ} \mathrm{C}$. The measured back-EMF waveform of BLDCM in electronic water pump is shown in Figure 7. It can be seen that the back-EMF waveform of the BLDCM is an approximate sine wave. The drive waveform of U-phase upper
MOSFET in 3-phase $\mathrm{H}$ bridge is shown in Figure 8. It can be seen that the drive waveform is a sinusoidal PWM signal, and the high level of the drive signal is $12 \mathrm{~V}$. The switching frequency of the drive signal is $20 \mathrm{~K} \mathrm{~Hz}$. The measured working current waveform of BLDCM is shown in Figure 9. It shows that the working current of the electronic pump motor is a sine wave. The effective value of the working current is $5 \mathrm{~A}$. Thus the input electrical power is $60 \mathrm{~W}$.

The performance test curve of electric pump motor is demonstrated in Figure 10. The test result shows that the flow of the electronic water pump is approximately linear with the input power. The lift gradually decreases with the increase of flow rate, and remains approximately unchanged at a low flow rate. It can be seen that the maximum lift of the developed electronic water pump is 3.4 meters, and the system efficiency of the pump is about $55 \%$.

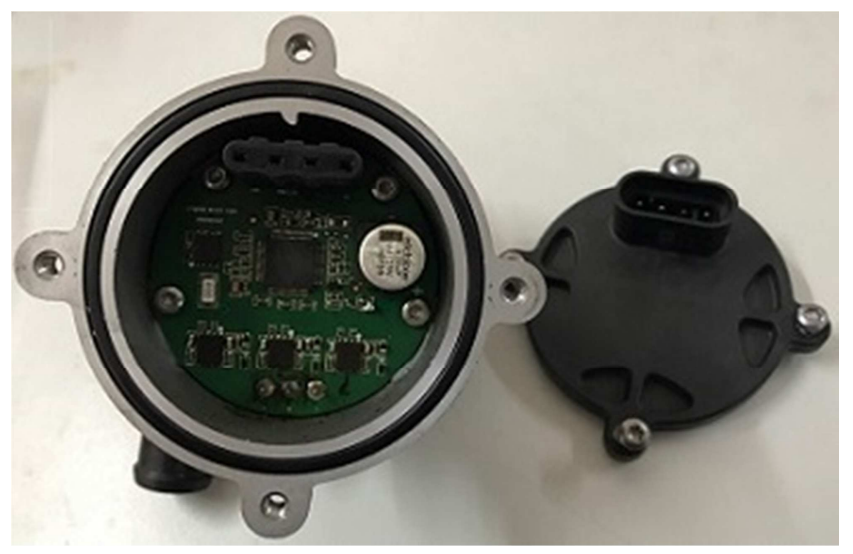

Figure 6. The physical picture of the developed electronic water pump.

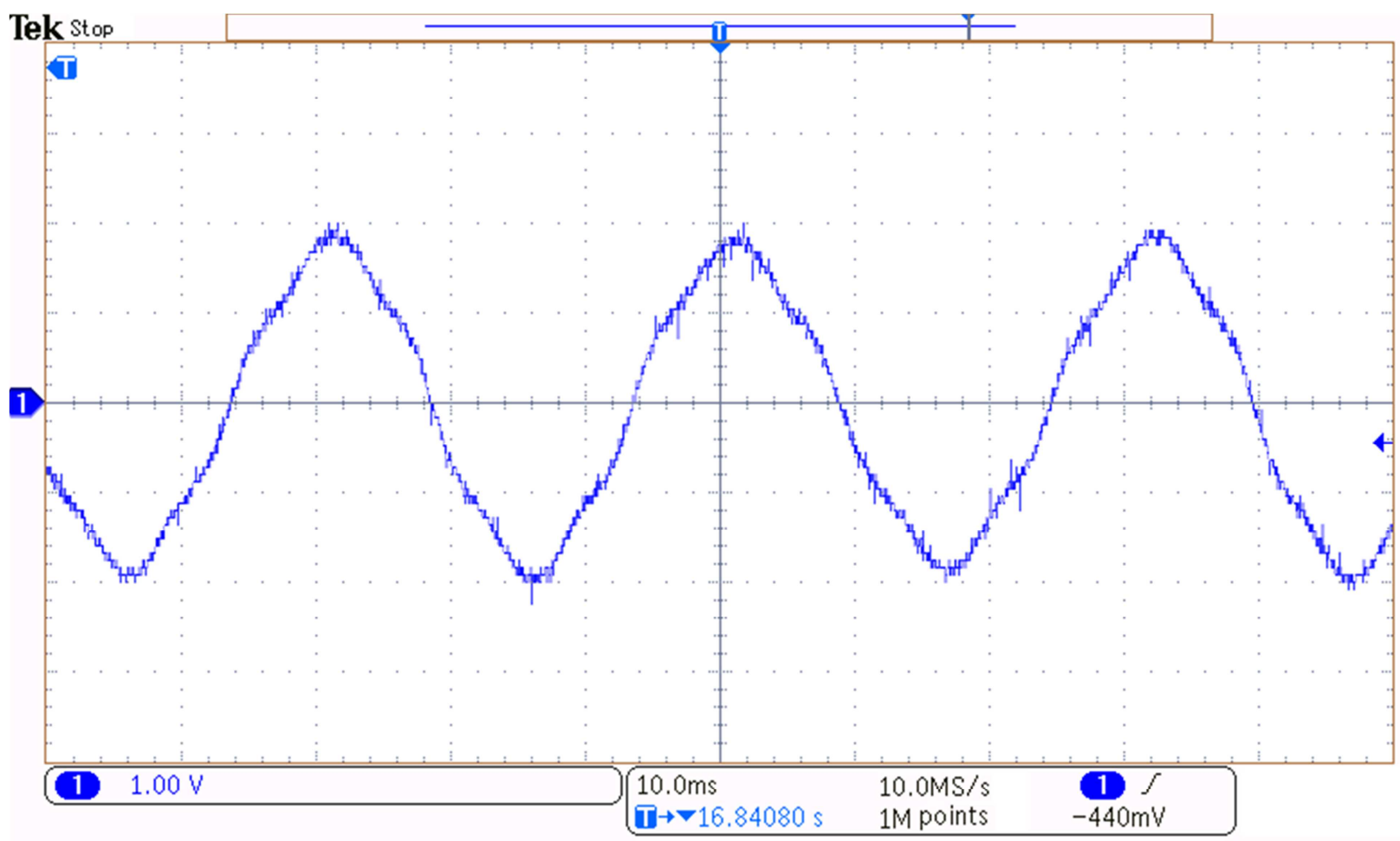

Figure 7. The measured back-EMF waveform of BLDCM. 


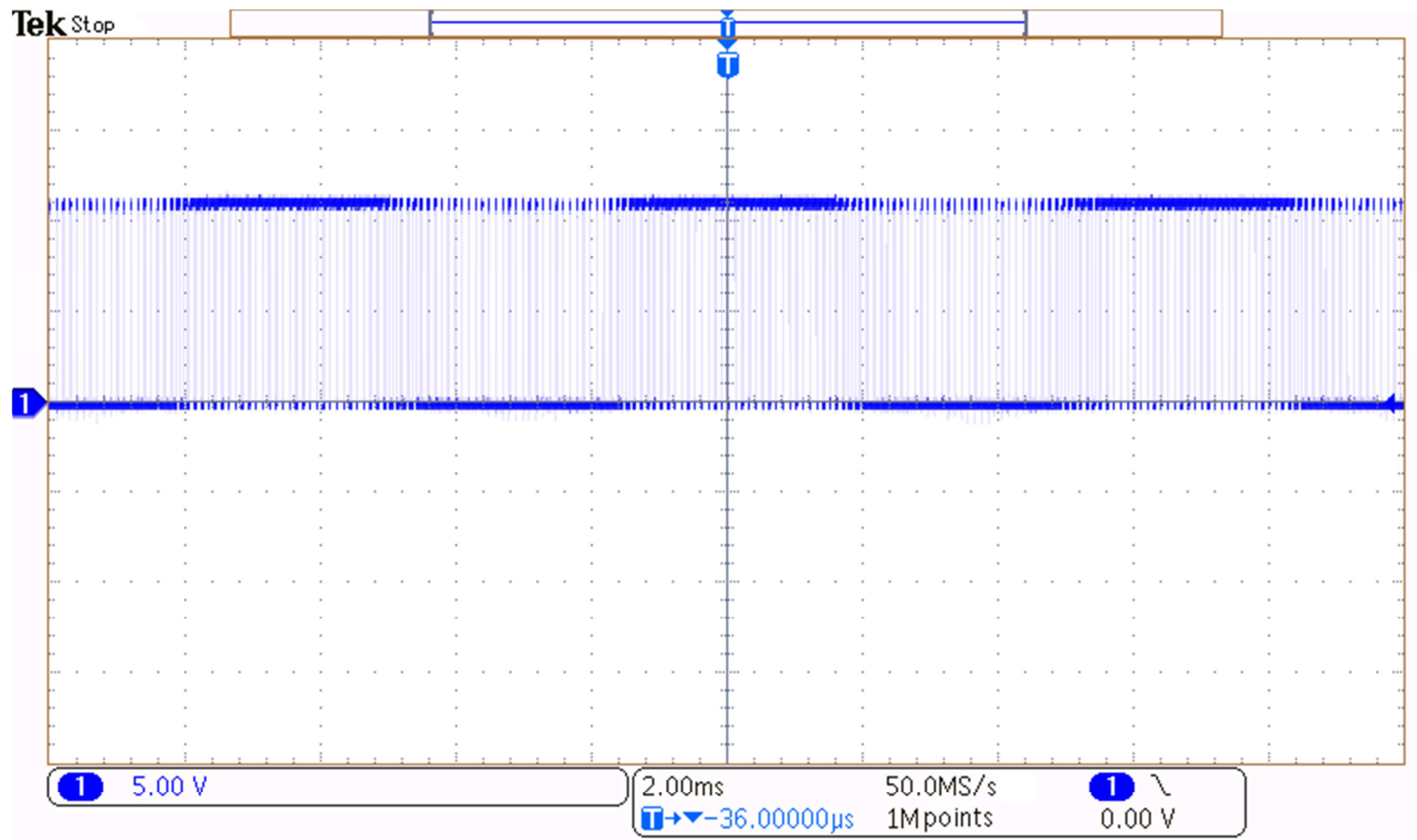

Figure 8. The drive waveform of U-phase upper MOSFET in 3-phase H bridge.

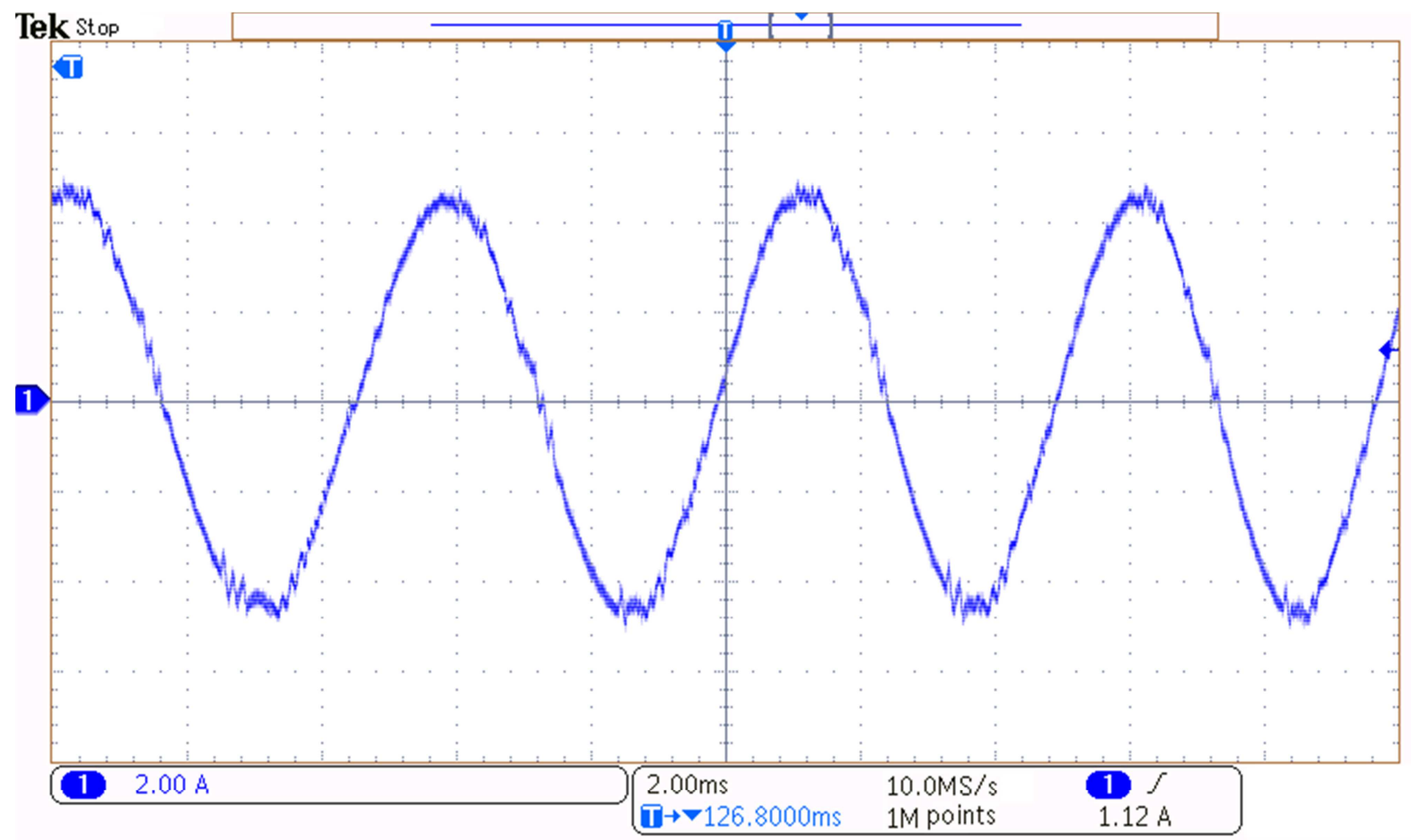

Figure 9. The measured line current waveform of BLDCM. 


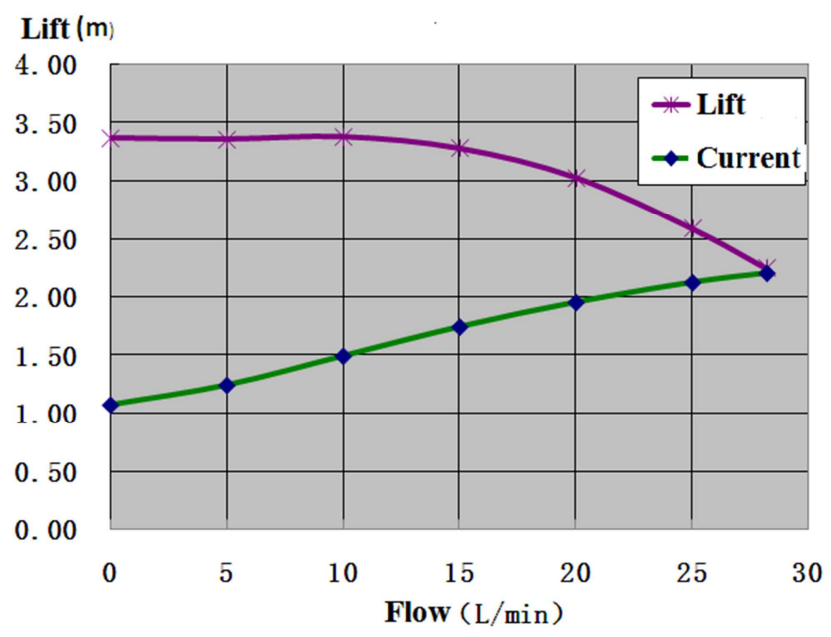

Figure 10. The performance test curve of electronic water pump.

\section{Conclusion}

A sensorless electronic water pump for automobile is designed and implemented in the paper. A novel sliding mode observer and Phase-Locked Loop are used in sensorless magnetic field oriented control. A robust $I-f$ startup strategy is used to guarantee a smooth transition from standstill to FOC mode. The introduced observer method can effectively reduce the sliding mode chattering and improve the position estimation precision. At the same time it preserves the robust estimation performance and low sensitivity to the variation of the motor parameters. The feasibility and effectiveness of rotor position detection technique based on SMO and PLL are verified by the experimental results. The aims of high control precision and high stability are attained. The targets of flow and lift for the electronic water pump are reached. The effectiveness and correctness of the proposed hardware design and the sensorless control are validated.

\section{Acknowledgements}

This work is supported by two of the Key Scientific Research Projects in Colleges and Universities of Henan province (No. 17A470003 and No. 17A150041), and one of the Major Science and Technology Special Projects in Henan province (No. 161100210700), as well as a Research Project "Research on the key technology of variable frequency air conditioning for new energy vehicles" of Henan provincial Science and Technology Department in 2018. We thank team members for their support and contributions to this study.

\section{References}

[1] Taeyeon Kim, Chungil Kim, Joon Lyou. A New Sensorless Drive Scheme for a BLDC Motor Based on the Terminal Voltage Difference. 2011 37th Annual Conference on IEEE Industrial Electronics Society (IECON), pp. 1710-1715, 2011.

[2] E. Babaei, M. B. Bannae Sharifian, R. Ajabi Farshbaf, S. H.
Hosseini. Verification of a New Method for PI Block Design of MRAS-Based Sensorless Speed Estimators. 2011 International Conference on Electrical Machines and Systems (ICEMS), pp. $1-6,2011$.

[3] Pradeep Kumar, Naveen Kaushik, Surender Dahiya. Simulation of Sensor less Speed Control of PMSM based on FOC Method with MRAS Adaptive Speed Estimator. 2013 Annual IEEE India Conference (INDICON), pp. 1-5, 2013.

[4] Nisha G. K., Lakaparampil Z. V., Member, IEEE and Ushakumari S. Four-quadrant Operation of Sensorless FOC Induction Machine in Field Weakening Region Using MRAS-Sliding Mode Observer. 2013 International Conference on Control Communication and Computing (ICCC), pp. 33-38, 2013.

[5] Sandeep Dhundhara, Pradeep Kumar, Yajvender Pal Verma. Sensorless Speed Control of PMSM Using Space Vector Pulse Width Modulation Based on MRAS Method. 2015 2nd International Conference on Recent Advances in Engineering \& Computational Sciences (RAECS), pp. 1-6, 2015.

[6] Naggar H. Saad, Ahmed A. El-Sattar, Mahmoud A. Gad. Sensorless Field Oriented Control Based on Improved MRAS Speed Observer for Permanent Magnet Synchronous Motor Drive. 2016 Eighteenth International Middle East Power Systems Conference (MEPCON), pp. 991-998, 2016.

[7] Bernadeta Wuri Harini, Aries Subiantoro, Feri Yusivar. Stability Analysis of MRAS Speed Sensorless Control of Permanent Magnet Synchronous Motor. 2017 International Conference on Sustainable Energy Engineering and Application (ICSEEA), pp. 34-40, 2017.

[8] Karthikeyan A, Prabhakaran K K, Venkatesa Perumal B, Nagamani C. Pseudo Derivative Feedback current controlled sensorless PMSM drive with Flux-Torque based MRAS estimator for low speed operation. 2017 IEEE International Symposium on Sensorless Control for Electrical Drives (SLED), pp. 115-120, 2017.

[9] Tang Ming, Gao Lin, and Liang Deliang. Sensorless Permanent Magnet Synchronous Motor Drive Using an Optimized and Normalized Extended Kalman Filter. 2011 International Conference on Electrical Machines and Systems, pp. 1-4, 2011.

[10] Nguyen K. Quang, Doan Duc Tung, Q. P. Ha. FPGA-Based Sensorless PMSM Speed Control using Adaptive Extended Kalman Filter. 2015 IEEE International Conference on Automation Science and Engineering (CASE), pp. 1650-1655, 2015.

[11] Tomasz Michalski, Carlos Lopez, Antoni Garcia, Luis Romeral. Sensorless Control of Five Phase PMSM Based on Extended Kalman Filter. 2016 42nd Annual Conference of the IEEE Industrial Electronics Society (IECON), pp. 2904-2909, 2016.

[12] Mohamad Syakir Termizi, Jurifa Mat Lazi, Zulkifilie Ibrahim, Md Hairul Nizam Talib, M. J. A. Aziz, S. M. Ayob. Sensorless PMSM drives using Extended Kalman Filter (EKF). 2017 IEEE Conference on Energy Conversion (CENCON), pp. 145-150, 2017.

[13] Rui Gao, Iqbal Husain, Jianyong Su. “An Improved Rotor Flux Estimation Strategy for Position-sensorless Control of Surface-mount Permanent Magnet Synchronous Motor," 2014 40th Annual Conference of the IEEE Industrial Electronics Society (IECON), pp. 404-409, 2014. 
[14] Guoliang Xiao, Xiaoguang Wang, Wenyi Tu, Lixun Tang, Huan Zhang, Kai Yang. A Sensorless Control of Surface-mount Permanent Magnet Synchronous Motor Based on Rotor Flux Estimation. 2017 20th International Conference on Electrical Machines and Systems (ICEMS), pp. 1-4, 2017.

[15] Ran Li, Guangzhou Zhao. Position Sensorless Control for PMSM Using Sliding Mode Observer and Phase-Locked Loop. Proceedings of the IEEE 6th International Power Electronics and Motion Control Conference, pp. 1867-1870, 2009.

[16] Justin Owen, Jeff Strouse. Sensorless Field Oriented Control Utilizing a Sliding Mode Observer for Control of an ActivelyRectified Permanent Magnet Synchronous Generator. 2011 Twenty-Sixth Annual IEEE Applied Power Electronics Conference and Exposition (APEC), pp. 1017-1021, 2011.

[17] Zhaowei Qiao, Tingna Shi, Yindong Wang, Yan Yan, Changliang Xia, Xiangning He. New Sliding-Mode Observer for Position Sensorless Control of Permanent-Magnet Synchronous Motor. IEEE Transactions on Industrial Electronics, vo1. 60, no. 2, pp. 710-719, 2013.

[18] Bing Liu, Bo Zhou, Haidong Liu, Jie Li, Long Wang, Qinglong Wang. Research on Initial Rotor Position Estimation for SPMSM. 2014 17th International Conference on Electrical Machine and Systems (ICEM), pp. 768-774, 2014.

[19] Saadaoui, A. Khlaief, M. Abassi, A. Chaari, M. Boussak. Position Sensorless Vector Control of PMSM Drives Based on SMO. 2015 16th international conference on Sciences and Techniques of Automatic control \& computer engineering, pp. 545-550, 2015.

[20] Vasilios C. Ilioudis. Chattering reduction applied in PMSM sensorless control using Second Order Sliding Mode observer. 2015 9th International Conference on Compatibility and Power Electronics (CPE), pp. 240-245, 2015.

[21] Hanan Mikhael Dawood Habbi, Afaneen Anwer Abood Al-Khazraji. FPGA based vector control of PM motor using sliding mode observer. 2015 Modern Electric Power Systems (MEPS), pp. 1-5, 2015. 2015 27th Chinese Control and Decision Conference (CCDC), pp. 6091-6096, 2015.

[22] Lisi Tian, Yang Liu, Jin Zhao, Jiajiang Sun. The sensorless control of IPMSM based on improved sliding-mode observer. 2015 27th Chinese Control and Decision Conference (CCDC), pp. 935-940, 2015.

[23] Saadaoui, A. Khlaief, M. Abassi, A. Chaari, M. Boussak. Sensorless FOC of PMSM drives based on Full Order SMO. 2017 17th international conference on Sciences and Techniques of Automatic control \& computer engineering, pp. 663-668, 2016.

[24] Ying-Shieh Kung, Risfendra, Yi-De Lin, and Liang-Chiao Huang. FPGA-Based Sensorless Controller for PMSM Drives Using Sliding Mode Observer and Phase Locked Loop. 2016
International Conference on Applied System Innovation (ICASI), pp. 1-4, 2016.

[25] Donglai Liang, Jian Li, Ronghai Qu. Super-twisting algorithm based sliding-mode observer with online parameter estimation for sensorless control of permanent magnet synchronous machine. 2016 IEEE Energy Conversion Congress and Exposition (ECCE), pp. 1-8, 2016.

[26] Mihai Comanescu. Speed, rotor position and load torque estimation of the PMSM using an extended dynamic model and cascaded sliding mode observers. 2016 International Symposium on Power Electronics, Electrical Drives, Automation and Motion (SPEEDAM), pp. 98-3, 2016.

[27] Hrishikesh Mehta, Vrunda Joshi, Pradeep Kurulkar. Implementation issues of sliding mode observer for sensorless field oriented control of PMSM using TMS320F2812. 2016 IEEE Symposium on Sensorless Control for Electrical Drives (SLED). pp. 1-6, 2016.

[28] Guozheng Li, Bo Zhang. Sensorless control of PMSM using Chua's circuit based on sliding mode observer. 2016 IEEE 8th International Power Electronics and Motion Control Conference (IPEMC-ECCE Asia), pp. 1840-1846, 2016.

[29] Chuanchuan Lin; Hong Guo; Shuping Meng; Xiaofeng Ding. Sensorless Control of PMSM Based on Modified Sliding Mode Observer. 2016 IEEE Vehicle Power and Propulsion Conference (VPPC), pp. 1-5, 2016.

[30] Vasillos C. Ilioudis. A model based sliding mode observer applied in PMSM sensorless control for speed and position. 2017 25th Mediterranean Conference on Control and Automation (MED), pp. 921-926, 2017.

[31] Yanling Yang, Hong Guo, Hao Qian. A sensorless control of SPMSM based on sliding mode observer with linear power drive method. 2017 43rd Annual Conference of the IEEE Industrial Electronics Society (IECON), pp. 4094-4098, 2017.

[32] Ons Ben Hamouda; Adel Khedher. PMSM under IOLC introducing a sliding mode position and speed observer. 2017 International Conference on Green Energy Conversion Systems (GECS), pp. 1-6, 2017.

[33] Wenjie Wang, Zexiang Li, Xiang Xu. A Novel Smooth Transition Strategy for BEMF-Based Drive Startup of PMSM. Proceedings of 11 th World Congress on Intelligent Control and Automation (WCICA), pp. 4296-4301, 2014.

[34] Z. Wang, K. Lu and F. Blaabjerg, A Simple Startup Strategy Based on Current Regulation for Back-EMF-Based Sensorless Control of PMSM, IEEE Transactions on Power Electronics, vol. 27 , no. 8, pp. 3817-3825, 2012.

[35] Li Niu, Jianyang Zhai, Xiong Liu, Youyi Wang, Amit Kumar Gupta. A Smooth and Fast Transition Method for PMSM SMO Based Sensorless Control. 2016 IEEE 2nd Annual Southern Power Electronics Conference (SPEC), pp. 1-6, 2016. 